\title{
On Mobile Technology in Context: Exploring Police Work
}

\author{
Daniele Pica and Carsten Sørensen \\ Department of Information Systems, London School of Economics and Political Science, London, UK
}

\begin{abstract}
This article aims to propose elements for a theory of mobile technology use. Modern organizations heavily rely on mobile devices. Mobile technologies pervade most work and social organizations in various cultural and institutional expressions. This paper explores issues related to mobile device usage within work activities of two distinct roles in a police force in the UK to put forth a theory of mobile device usage across various work roles. It advances the idea that usage of mobile technologies is linked strongly to work conditions and that, in order to increase usage within organizations, we must employ a triangulated analysis to understand both the relation with the environment of work as well as the relation with information.
\end{abstract}

Keywords: mobile technology, virtual reality, work, police work.

\section{Introduction}

As organizations are increasingly introducing personal mobile devices to support work, the need for understanding the dynamics between mobile devices, organizations and individuals' work assumes a privileged position in information systems research. In fact, both academia and industry research efforts focus on maximizing the interaction between individuals and mobile devices [29].

This is based on the idea that mobile devices will bring about fluid work organizations to sustain a post-modern era of efficient and ad-hoc services available 'anytime, anywhere' through the increased mobility and connectivity of professionals [16]. However, planning and implementing a mobile enterprise strategy can be puzzling. For mobile devices to be a success, these must meet various needs of the end-users [25]. Achieving this goal is not easy, in part because of the novel state of mobile systems' studies. In fact, as Johnson [13] states, the conventional methods of human-computer interaction (HCI) need to be reconsidered because they are not sufficient to address the changing contexts and interactions that mobile technology establishes.

The use of mobile technologies signifies a stronger connection between the human and the technical aspects, and also implies a stronger influence of the context of interaction. It can indeed be argued that the mere separation between the technology and the context of use is artificial, as we experience increasingly embodied interaction [10]. The aim of this paper is to explore the relationship between the context of work activities and mobile information usage. We aim to explore pertinent contextual factors determining particular modalities of usage of mobile technologies.

This paper offers an analysis and a discussion of the different practices of usage of mobile technologies in organizations presenting as a particular case the police. The police are one of the archetypical examples of organizations that rely on mobile technologies. Historically, technology has transformed police practices. From the introduction of the telegraph in the late 1800's to the usage of two-way radios and computeraided dispatching during the 1900's $[1 ; 30]$, information technologies have radically changed the organization of police work and, with it, the expectations of various police services [23]. The analysis of the case study coupled with a theoretical discussion on virtual communication points towards particular characteristics of mobile devices in relation to the context of use highlighting the following two defining aspects of mobile device interaction in context: active 
versus passive environments and structured versus unstructured work.

The structure of this paper is as follows. We start the paper by briefly looking at the method of research. Following, we present the case study. We then address the specific characteristics of mobile devices within the context of work organizations, and develop a model for understanding the relationship between work activities and mobile devices. Finally, we present concluding remarks and future areas of research.

\section{Method}

In order to achieve the research aim, we build a qualitative case study. Inspired by new sociotechnical theories $[3 ; 4 ; 8 ; 27]$, we do not look at technology as a self-contained entity, but rather as a highly contextualized tool which is affected by the social setting in which it is deployed and which in turn affects the social setting. Consequently, central to this research is the belief that technology is never an isolated body in a decontextualized space, nor is it self-contained. Technology is significant, as much for its functional qualities as for the degree to which it is part of a persuasive narrative that binds the object and the viewer together in a shared system of beliefs. No technology exists for its own sake, alone, or alienated; rather, it is interwoven in the very historical fabric of the society it has been appropriated in.

Following these beliefs, the case study itself consisted of two intense days of observations ( 2 half day observation of the actual work performed by the police officers), interviews ( 3 in-depth interviews) and focus groups (2 twohour focus groups with 4-6 people) with police members from forensic science and community services. The methodology consisted of two complimentary interpretive research techniques that produced qualitative data:

- Interviews aimed at understanding both the actual work practices together with the usage of mobile technologies and the perceived needs of various police roles and,

- Observations (where possible) of the actual work and subsequent usage of mobile technologies.

\section{Two Police Work Roles}

During the case study we concentrated on two differing and in some way contrasting roles within the police: the Scenes Of Crime Officer (SOCO) and the Community Security Officer (CSO). Informed by socio-technical theories, we did not look strictly at issues of design or ergonomics, but instead focused on issues of interaction in locus and the surrounding environment of work, what Suchman (1987) would define as situated action. We concentrated on constructing a picture of the typical work activities these two roles accomplish in their daily work. In particular, we aimed at documenting the officers' information management activities and the relation of these activities to various mobile technologies.

\subsection{SOCO's Work}

A Scenes Of Crime Officer (SOCO) collects, documents, records and lends authority to forensic evidence at crime scenes. SOCOs generally hold postgraduate degrees in relevant subjects such as chemistry or forensic biology. Initially, in order to become a SOCO, a candidate will enrol in nine weeks intensive formal training in photography, pure forensics such as finding DNA and carpet fibres, fingerprints analysis, and assessment through the creation of scene of crimes scenarios.

During their subsequent daily work, a SOCO typically spends half of the time at the police station where he or she accesses various information systems, and carries out chemical treatment. The other half of the typical working day is spent in the field, collecting evidence. The SOCO is arguably a group within the police force who will benefit from information technologies in general and mobile technology in particular. Their work is mostly 'information work'. In the constabulary studied, all SOCOs were provided with a GSM enabled laptop connected to the police network, and a mobile phone. However, despite many claims of mobile technologies enabling the mobilisation of information 'anytime and anywhere,' location and in particular the replication of an office environment is still important for this particular role. The job of a SOCO generally emerges 
during the day. They respond to new crime incidents logged in the Crime Information System (CIS), either from the office, or when they are on the move, from their laptop, or through mobile telephone calls. Generally, the CIS was not user friendly to access when on the move, since it tended to lock out the user, with a restart time of around 5 minutes, which in the daily rhythm of a SOCO was considered a substantial disruption. As a result, laptops were only rarely used in the car. For security reasons and due to respect for the victims of crime, the laptop was not used within scenes of crime. Furthermore, once at the scene of crime, the SOCO needed to divert all their attention immediately towards obtaining a proper overview of the situation.

Printouts from the CIS forms were typically used to begin the activity of surveying the crime scene. The primary aspect of SOCO work is gathering proof related to the crime. SOCOs also gather intelligence through aggregating and processing information. The way in which a SOCO obtains information about the crime scene relies on the reports generated by the police officer filing the crime and on the conversations with the victims of crime. The daily work of a SOCO generally consists of codifying observations, evidence and conjectures according to a complex classification structure that recently has been formalised and computerised in a bespoke application supporting SOCO work as well as the management of workflow processes related to the evidence collected. Averages of five jobs are completed per day, and this includes a substantial number of mobile phone calls to coordinate as well as travel from site to site. After completing the jobs, a significant amount of time is spent documenting and storing exhibits as well as writing up reports. The reporting is done on a paper-sheet at the crime scene. It takes about 10 minutes for each job to update the system and two hours total to finish up the daily office work. This is generally done between 2 and $5 \mathrm{pm}$, which represents a significant proportion of a working day.

In terms of the types of crime SOCOs attend, burglaries and theft account for around $85 \%$ of the cases and $10 \%$ are minor theft and vandalism. $5 \%$ are the major crimes such as murder. The success rate of a SOCO is constructed according to the number of arrests made as a result of the evidence collected. Obviously, as the sole representative of the police force at the scene of crime, the SOCO will engage in the emotional support of the victim. This implies that SOCOs often will engage in Public Relations on behalf of the Department. A significant proportion of SOCO work is classified as "small crime" and will not be solved because of lack of evidence or because of low priority given the scarcity of resources. Summarising, SOCO's work entails 3 major elements:

- Proof gathering

- Reassurance of victims

- Intelligence gathering

The SOCO information flow can be characterised as follows. The SOCO takes notes from CIS printouts. Often they will need more information from the officer that has entered information about the crime into the CIS as the level of detail, and the selection of information often will not match the need of the SOCO. Following, they talk to the victim and make notes while they examine the crime scene and collect the physical evidence that will be sent back to the laboratory for examination. On their report sheet they document text, diagrams, sketches of shoe marks and pictures. The latter is seen as the richest kind of proof gathering.

Each item of evidence is sealed in a plastic bag and sealed off using labels that are signed and tamper-proof. The SOCO will bring along various cartons and wrappings and will often be required to be creative in order to package and seal oddly-shaped evidence collected. They generate an ID for each evidence item collected and record the item on a list with the matching ID. The white label containing the ID is signed and each subsequent person using the evidence will sign and date the label. The documentation is kept in the office and the original receipt is kept by the SOCO. After processing 2-3 scenes of crime, the SOCO would typically return to the office, where they submit paperwork. According to the SOCOs themselves, even if SOCO work seems highly geographically mobile, there is still the need for an office for two reasons: to hand over the physical evidence for storage and to finish paperwork, in the form of transcribing every note taken at the crime scene. After returning evidence to the station, the laboratory carries out tests on DNA and fingerprints. 


\subsection{CSO Work}

The Community Security Officer (CSO) is a highly localized police officer acting as a bridge between a local community and the police force. A CSO generally patrols the community on foot or by bicycle and has a personal relation with a significant proportion of the community. The CSO generally considered the car as alienating; it was seen as essential to be in the field and have extensive local mobility. The CSOs generally perceived the job as a continuous involvement with the community, and they described their function as one of reducing the fear of crime in the community. Any formalized system could endanger the information, losing the local flavour. The way in which they entered information into the system was seen as crucial for the following investigations by other police roles. In a way, the information by being so localized was not suitable for sharing in a largescale community. As one CSO put it, the information was good for an insurance claim but not for community building — the main job of a CSO.

The CSO had extensive and continuous contact with many community institutions and, generally, also volunteered at local schools. They built their own information gateways for the communities through e-mail and web pages. The information CSO looked at and shared within the organization were with: colleagues over a cup of coffee in the same office (in order to share information about an area; LIO (Local Intelligence Office - which, according to the CSO, were the most likely to get a positive ID on a criminal); Domestic violence team; dog team; ID2 (Intelligence Surveillance Team in plain clothes who used the information from CSO to survey people and make arrests); and the press office which helped community awareness and potentially gave good publicity. In addition, the CSO had an extensive network outside of the organization, such as the local council, housing associations, schools and social services. Some of the members of the public had the mobile phone numbers of their local CSOs.

During the day the CSO would - either initially or towards the end - log into the CIS to check for incidents in her area, as well as make and receive phone calls on the mobile. A lot of coordination was conducted through and information passed over the mobile phone. Sometimes this information was 'unofficial.' The CSO also kept in contact by e-mail with relevant members of the community, for example students at the University and families in the community. One of the CSOs sent bulletin e-mails to targeted members of the community to keep them updated about recent events, and also received anonymous information about drugs and fights.

As far as the structuring of the job was concerned, the CSO were self-tasking, and they generally decided what to do, depending on the perceived urgency of the situation. The CSO wanted to be seen in the field. When a CSO reported a crime, they usually did so through the phone or the police radio. The local information gained by the CSO was put into a local information system. However, some of it was only used personally and kept in a non-networked file. This meant that other officers did not have the benefit to access it. One of the concerns of CSOs was that through the increased computerization and formalization of information system their job would shift towards being mostly clerical as opposed to centred in the field.

As one CSO put it, he was 'tasked by the public.' For them, in fact, timeliness was critical in solving problems. Differently from the SOCOS, the CSO would feel comfortable networking their computer in the victims' houses or sites. The CSO would like a tailored version of CIS that would filter out irrelevant information - for instance getting only local area CIS. It was claimed that this would save time and maybe enable a higher degree of out-of-office work. The CSO felt the need of having both laptops and PDAs. Given that most of the work was conducted in the streets of the community, such solutions were described as difficult to implement. In addition, it was noted that the confidence in the system was less than in the case of SOCO, because of the highly localized nature of the CSO's job and the timeliness of the response.

\subsection{Contrasting the Two Roles}

The case study illustrates that the two police roles differ in their context of work in significant ways. For instance, where the CSO works mostly in the street, the SOCO moves from house to house, from crime scene to crime scene. In addition, while the SOCO particularly deals with inanimate objects (forensics 
evidence), the CSO deals with people. Most importantly, the crime scene for the SOCO is one that has been already resolved by police officers, while the CSO's crime scene is emergent and uncertain. The objectives of the two roles also differ in significant ways. SOCOs have done their job when their work leads to an arrest; CSO, on the contrary, have done their job when the community is united and secure, and they generally seek to avoid conflict.

The difference in the context of work is illustrated also by the different usage of mobile technologies. The SOCO's main tool is the laptop computer. The police radio is seldom used by SOCO, while it is the main tool at present time for the CSO. The mobile phone seems to be used equally by CSO and SOCO. However, while the CSO use the mobile phone for all kinds of communication - from keeping in touch with colleagues to keeping in touch with community members - SOCO mostly use the mobile phone to communicate with the victim prior to arrival.

The view of mobile devices by the two roles also differs. SOCO require an intense data communication throughout their visit at the crime scene, and are required by law to document every action they take. The CSO's job is more abstract. It is about community building and does not require a continuous engagement with information. The CSO needs information in a quick way only when the environment demands it. The SOCO, on the contrary, is tasked by the information already contained in the system. SOCOs interviewed voiced the desire to be as much as possible in the field, be mobile, and go back to the station only to put recorded evidence into storage. Likewise, the CSO expressed a desire to be more time in the street and access the CIS directly from the field.

In addition, time of engagement and disengagement from technology plays an important part when looking at mobile device usage (e.g. CSO when responding to emergencies). If we consider the information managed within the police, then we can argue that whilst CSO could deploy mobile technologies in order to refine the information retrieved from the environment of work for the organization, the SOCO depend on that information to generate intelligence when feeding it back into the environment.

\section{Understanding Mobile Devices}

This section will discuss a particular analytical lens for understanding and researching the phenomenon of interaction with mobile technologies in geographically distributed work arrangements. The purpose of this framework is to conceptualize the phenomenon of interaction through and with mobile information and communication technologies, and as such contribute to alleviating the relative lack of theoretical approaches to the study of mobile technologies [14].

The step we take in this section is to uncover the main characteristics of mobile devices as used in work activities. These are not to be regarded as negative or positive aspects of current technologies, but rather as properties of mobile systems in action. Work can be generally divided into two distinct categories: structured one which requires a high degree of routinized steps and a low degree of complexity - and unstructured - one which requires a high degree of improvisation [7] and has a high degree of complexity [24]. Our contention is, therefore, that the nature of work is the one that determines the successful or unsuccessful usage of mobile devices.

The main property of mobile devices, as that of communication technologies such as the telephone, is that of creating a virtual environment of interaction $[18 ; 19 ; 20]$. Thus, the mobile phone or laptop, for instance, is a device that allows us to transport a spatially distant, or absent, reality containing people and objects and to interact with it [15]. Of interest to us is the absent present, an oxymoron which draws attention to the way a sense of 'belonging to a place' can be altered and redefined by new technologies [11]. We can 'belong' to a communicative network rather than, or at the same time as, a physical space. In effect, the importance of physical environment/situation diminishes. The emotional elements that have vanished in relation to physical location are moved to a social level; 'that is the sense of identification, familiarity, stability and security [11]' Many social theorists have tried to define this kind of reality as a virtual one in that we cannot apprehend it in physical terms $[2 ; 12]$. 


\subsection{Virtuality, Mobile Technology and Work}

In order to understand virtuality we must understand how it came about. With the advent of literacy (and, later, of print and electronics) our attention began to shift away from natural, face to face, communication [26]. We arrived at a point of modularization where only one or two of the human senses are predominant $[18 ; 19 ; 20]$. In a sense, we become a big ear or a big eye, because the symbol system demands largely only one or at most two of our senses. And so, for instance, we learned to answer a phone call interrupting a 'physical' interaction with someone. This act illustrates how we are forced to divert attention from interpersonal physical communication to a virtual conversation.

The physical environment affects our usage of mobile equipment $[6 ; 9 ; 28]$. Various studies point out that the physical environment can constrain various work activities to the point where the use of mobile devices is impossible (e.g. the case of CSO when walking in the street). In addition, there are many social conventions that determine the ways in which we initiate interaction [21] (e.g. The SOCO not using the laptop at the victim's house). Thus, the real environment has the potential to restrict or to increase our interaction with the virtual. In fact, individual orientations toward objects are continually shifting and being transformed with respect to the ongoing interaction and activities [22]. The mobile device, by allowing us to interact with virtual rituals, makes us act in different ways within our real environments.

The diminishment in natural communication has permitted the emptying of physical presence in space [11] and thus a weakening of the link between content and context in favor of a precise symbol system [17]. There is a stress on individuality (for example the reading of a book requires our complete visual attention and a non-oral environment); secondly, there is a $d e$ contextualization of being. While primary orality was context-bound, the initial virtuality, by separating the author from the text (in the case of the book), creates an abstract and fixed space [26]. In order for information to be transmitted across contexts we need a form of standardized codification [18]. The standardization itself is separated from the context-embedded action of individuals. This is necessary for mobility. The abstraction itself is needed for objects (etc.) to be transferred across contexts. This tells us that technology cannot be locally constructed, that the specificity or flexibility of technology depends upon its ability to cross contexts [18]. In addition, cross-contexuality, since it relies on an infrastructure, has a strong self-referential character. This is evident when we look at the historicity of technological artifacts and how they inherit the functional and symbolic characteristic of older technologies [5]. In the end, mobile devices, by virtue of being a system, force a user to a greater or lesser extent to conform to a set of guidelines and bring them across contexts. To sum up, the two main properties of mobile technologies are:

- Mixture between virtual and real environments

- Higher de-contextualization of information because of a precise symbol system.

\subsection{Work in Terms of Information and Environment}

To sum up, firstly, there is a mixture between virtual and real environments; thus, it is important to look at the work relation with the environment. This can be active or passive. An active relation can be characterized as one that requires constant attention to the physical space of interaction (e.g. CSO patrolling the street). The physical space is the one dictating the line of action to be followed by the worker. Thus it is full of emergent details. Examples of such work can be the ones that involve either physical attention (e.g. a telephone engineer), visual attention (e.g. a policemen walking across a high crime area) or a mixture of both. The success of mobile devices in active work environments is thus limited. We can argue that only voicesupported services can be adopted as in the case of CSO.

Secondly, there is a higher de-contextualization of information because of a precise symbol system. This precise symbol system can influence work in positive or negative ways, depending on the nature of the task. Work task can be loosely categorized as structured or unstructured. A structured work task can be defined as the one that has a repetitive character in its information access for problem resolution as in the case 


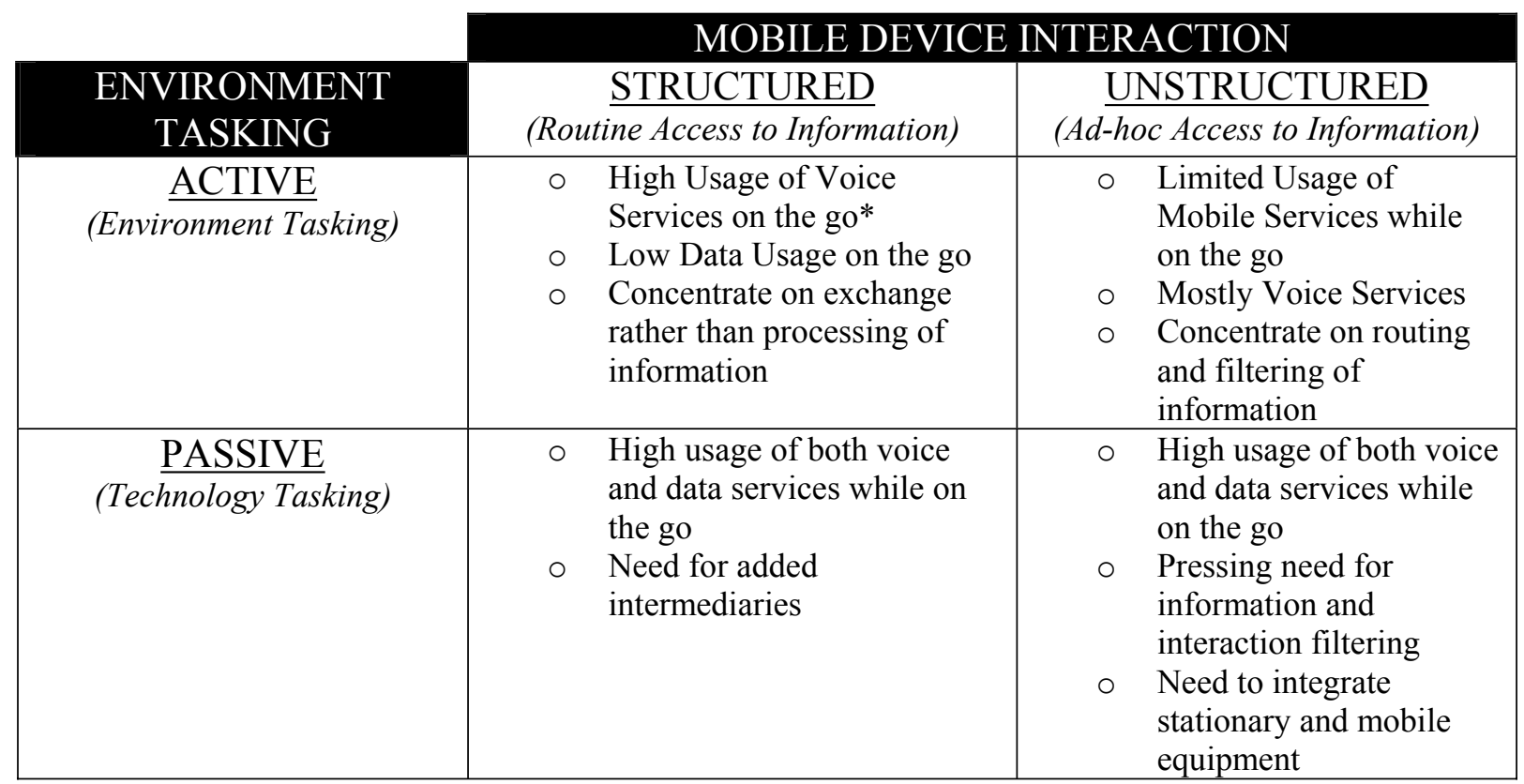

* "On the go" refers to usage of mobile device while performing mobile work.

Table 1. Mobile Technology Use in Relation to Work Environments.

of SOCO. An unstructured task is the one that has to be supported by a dynamic access to information through multiple channels. For instance, a directory assistance operator performs mostly structured information gathering, while a market analyst relies on multiple channels of information that are dynamically changing.

Table 1 encapsulates the ideas developed. In the table we can locate the two roles analysed in the case study. The SOCOS would be located in the Passive/Structured cell. The success of mobile applications in this cell is potentially high, because it is mostly related to data access. The CSO would be located in the Active/Unstructured cell. The adoption of mobile applications in this cell is high. However, the supported applications should mostly be voiceenabled, because of the active environment of work.

The matrix shows that the more intense the relationship with the environment gets in terms of the emergent character of the situation, the more data services that require visual attention and particular physical postures lose value (e.g. the CSO). What gains in importance in active situations are voice services. In active situations, coordinating activities are important. For instance, when the CSO notices a situation that requires police attention, she will call for help.
The best way to communicate in time critical situations is by voice, being the more contextualized and immediate information modality [14]. In the case of SOCO, where the usage of data is high and thus the de-contextualization modality is high, there is a need for added intermediaries that will solve contextual problems that cannot be handled by the system. For instance, the short term improvement of SOCO work, as demanded by SOCO themselves, would be to employ an expert administrator that could assist in doing the administrative work of documenting the findings in the system and also help coordinate jobs between individual SOCOs. In the long term, there is a need for the introduction of mobile technology that will minimize the replication of information and that, at the same time, does not get in the context of interaction. As an example, Tablet PCs were mentioned as a means for supporting the recording of information, with the additional requirement of a ruggerised version since fingerprints primarily are lifted using aluminum powder, which is highly destructive to computer technology. Furthermore, CSO demanded a good filtering of information, in that they have very little time to react to it when engaged with an incident. If mobile devices are used for a support function (communicating versus structuring of work) as 
in the case of CSO, it permits a higher flexibility in the daily organization. Thus, while the SOCO need more of a synchronization function which structures their work, the CSO need real time access to information and to communicate with different parts of the organization. The matrix can be seen as encapsulating also other kinds of work environments and is not meant only for understanding the interaction modalities in relation to the environment in a policing context.

\section{Conclusion}

In this paper, we have conducted a discussion of the relationship between work activities, the use of mobile devices and the work context. Mobile devices influence the way information is gathered, generated and used. This means that it is important to consider how data (we use data in a loose sense to look at voice, images and text transmissions) flows, is accessed and interacts with the environment of use. This discussion was introduced by a case study of two roles within the UK police force, Scenes of Crime Officers obtaining and recoding forensic evidence, and Community Security Officers providing valuable policing to localized districts. The aim of the analysis has been to further extend the theoretical discussion on mobile technology use. The paper asks what the contextual factors affecting the usage of technology are. This becomes apparent when considering police work where some roles are tasked by the environment and others are not. Similarly, some police roles will critically rely on structured information systems serving as a stable source of work process documentation and information. Other roles will need more ad-hoc access to a variety of information sources. Mobile devices are not an over-arching solution. There are situations in which their usage is inappropriate or in which it can be ameliorated by changing the way in which they are used and thus the modality of interaction. This is to say that time does play an important part when looking at technology. The shrinking in the time it takes to configure resources questions the basis on which these decisions are made. To conclude, we propose a matrix that encapsulates a triangular relation of workers with both mobile devices and the environment based upon the ideas of active and passive environments and structured and unstructured work tasks. There are clearly other contextual factors that can influence mobile device usage (e.g. risk, time, infrastructural arrangements etc.). However, in this paper we confined ourselves to the most relevant ones to the policing context, as also suggested by the theory of virtuality. This paper marks an initial step in the investigation of the relationship between mobile devices and the context of work, and we strongly believe that such analyses are necessary for further understanding the value of mobile technologies. In conclusion, the usability of mobile and wireless devices cannot be understood by considering the technical functions alone. The contextual factors relating to information usage modality and environmental engagement are important elements of analysis. Further research is needed to understand and test the contextual factors influencing the usage of mobile technologies.

\section{Acknowledgements}

First and foremost, we would like to extend our gratitude to all the police officers sharing their working lives with us. Thanks to David Allen who participated in the initial empirical study. Thanks to the two anonymous reviewers. Also thanks to Steve Sawyer and Urban Nuldén who both provided important comments along the way. The end result is of course entirely our own responsibility.

\section{References}

[1] Agar, Jon, Constant Touch: A Global History of the Mobile Phone, Icon Books, Cambridge, 2003.

[2] ANDERSON, B., Imagined communities: Reflections on the origin and spread of nationalism, Verso, London, 1983.

[3] Berger, Peter L. And Thomas Luckmann, The Social Construction of Reality, Anchor Books, Garden City, NY, 1966.

[4] BIJKeR, WiEBE E., Of Bicycles, Bakelites, and Bulbs: Toward a Theory of Sociotechnical Change, MIT Press, 1997.

[5] Bolter, J.D. AND R. GRUSIN, Remediation: Understanding New Media, MIT Press, 1998. 
[6] Brown, BARry AND Kenton O'Hara, Place as a practical concern of mobile workers, Environment and Planning, 2001.

[7] Ciborra, C.U., Notes on improvisation and time in organizations, Accounting, Management and Information Technologies (1999), vol. 9, no. 2.

[8] DAHLBOM, Bo, The New Informatics, Scandinavian Journal of Information Systems (1996), vol. 8, no. 2, pp. 29-47.

[9] DiX, ALAN, TOM RODDEN, NIGEL DAVIES, JONATHAN TREVOR, ADRIAN FRIDAY, AND KEVIN PALFREYMAN, Exploiting Space and Location as a Design Framework for Interactive Mobile Systems, ACM Transactions on Computer-Human Interaction (2000), vol. 7, no. 3, pp. 285-321.

[10] DOURISH, PAUL, Where the action is: The foundations of embodied interaction, MIT Press, 2001.

[11] Fortunati, LeOPOLdINA, The Mobile Phone: New Social Categories and Relations, University of Trieste, 2000.

[12] Graham, G., The Internet: A Philosophical Enquiry, Routledge, New York, 1999.

[13] JoHnSON, P., Usability and Mobility: Interactions on the move, in First Workshop on HCI for Mobile Devices, Glasgow, ACM, 1998.

[14] KaKiHara, MaSaO, Emerging Work Practices of ICT-Enabled Mobile Professionals, PhD Thesis The London School of Economics and Political Science, 2003.

[15] Kakihara, Masao And Carsten Sørensen, Mobility: An Extended Perspective, in 35th Hawaii International Conference on System Sciences, Hawaii, USA, 2002.

[16] Kakihara, Masao And CARSTEn SøREnSEN, Mobile Urban Professionals in Tokyo: Tales of Locational, Interactional and Operational Mobility, in 2nd Mobility Roundtable, Stockholm, 2003, ed. Bertil Thorngren.

[17] KalliniKos, Janis, The Age of Flexibility, Academia Adapta, Sweeden, 2001.

[18] KALliniKOS, JANIS Recalcitrant Technology. Crosscontextual Systems and Context-embedded Action, in Department of Information Systems, London School of Economics, London, 2001.

[19] KalliniKos, Jannis, Technology and Society, Accedo, Munich, 1996.

[20] KALLINIKOS, JANNIS, Virtuality and Virtual Organizations, Department of Information Systems, London School of Economics, 2002.

[21] Ljungstrand, Peter, Context Awareness in Mobile Telephony, in Proceedings of Wireless World Workshop, Digital World Research Centre, Guildford, 2000, United Kingdom.

[22] LufF, Paul and Christian Heath, Mobility in Collaboration, in Proceedings of ACM 1998 Conference on Computer Supported Cooperative Work, ACM Press, 1998, pp. 14-18.
[23] Manning, Peter K., Policing contingencies, University of Chicago Press, Chicago, 2003.

[24] Mathiassen, LaRs And Jan Stage, The principle of limited reduction in software design, Information Technology \& People (1992), vol. 6, no. 2-3, pp. 171-185.

[25] OLSHAVSKY, R., In telematics, no technology is a panacea (2002),

http: //www. cooper. com/newsletters/ 2002_08/no_telematics_panacea.htm

[26] Ong, Walter J., Orality and Literacy: The Technologizing of the Word, Routledge, London, United Kingdom, 1988.

[27] ORLIKOWSKI, W., The Duality of Technology: Rethinking the Concept of Technology in Organizations, Organization Science (1992), vol. 3, no. 3, pp. 398-427.

[28] Perry, Mark, Kenton O'HARA, AND AbigaIL SELLEN, Dealing with Mobility: Understanding access anytime, anywhere, in TOCHI, 1999.

[29] PiCA, DaniEle And Masao KaKiHARA, The Duality of Mobility: Understanding Fluid Organizations and Stable Interaction, in ECIS 2003, Naples, Italy, 2003.

[30] StANDAGE, TOM, The Vicorian Internet, Weidenfeld \& Nicholson, London, 1998

Received: July, 2004

Revised: August, 2004 Accepted: September, 2004

Contact address:
Carsten Sørensen
Department of Information Systems
London School of Economics and Political Science
Houghton Street
London WC2A 2AE
United Kingdom
e-mail: c.sorensen@lse.ac.uk

CARSTEN SøRENSEN is a Senior Lecturer in Information Systems at The London School of Economics and Political Science, United Kingdom. He holds a BSc. in mathematics, an MSc in computer science and a $\mathrm{Ph} . \mathrm{D}$. in information systems from Aalborg University, Denmark. His research investigates how ICT shapes and is shaped by working practices, most recently mobile and wireless technologies. Core concerns in his research has been the management of social interaction in distributed settings, in particular considering the increased mobilisation of interaction and the subsequent struggle for mobile individuals to engage in fluid interaction. Dr. Sørensen has through the past 14 years been affiliated with a number of Danish, Swedish and British institutions. In 2002 Dr. Sørensen initiated a research network in mobile interaction called mobility@lse (http://mobility.lse.ac.uk/), which aims at drawing together academics and practitioners with an interest in studying the profound changes to society, individuals and technologies in the mobile society of the $21^{\text {st }}$ Century. He has since 1997 been Research Director of Laboratorium for Interaction Technology (http://laboratorium.htu.se) at Trollhättan Uddevalla University, Sweden, which is actively engaged in large regional development projects funded by the European Union, Swedish funding agencies and local industries and public organizations. 
DANIELE PICA is a PhD. student in Information Systems at The London School of Economics and Political Science, United Kingdom. He holds a BSc. in Business Administration from the University of Southern California, United States of America and a MSc. in Administration, Design and Management of Information Systems from The London School of Economics and Political Science, United Kingdom. His research investigates the problems associated with the use of mobile and wireless technologies in public law enforcement institutions. The core concerns in his research are the management of work in distributed settings in police organizations, and the consequences of mobile technologies for police operations. 